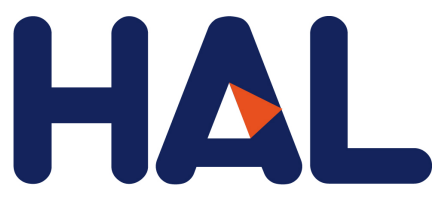

archives-ouvertes

\title{
Control of aversion by glycine-gated GluN1/GluN3A NMDA receptors in the adult medial habenula
}

\author{
Y. Otsu, E. Darcq, K. Pietrajtis, F. Mátyás, E. Schwartz, T. Bessaïh, Sarah
} Abi Gerges, C. Rousseau, T. Grand, S. Dieudonné, et al.

\section{- To cite this version:}

Y. Otsu, E. Darcq, K. Pietrajtis, F. Mátyás, E. Schwartz, et al.. Control of aversion by glycine-gated GluN1/GluN3A NMDA receptors in the adult medial habenula. Science, American Association for the Advancement of Science, 2019, 366 (6462), pp.250-254. 10.1126/science.aax1522 . hal-02340215

\section{HAL Id: hal-02340215 \\ https://hal.sorbonne-universite.fr/hal-02340215}

Submitted on 30 Oct 2019

HAL is a multi-disciplinary open access archive for the deposit and dissemination of scientific research documents, whether they are published or not. The documents may come from teaching and research institutions in France or abroad, or from public or private research centers.
L'archive ouverte pluridisciplinaire HAL, est destinée au dépôt et à la diffusion de documents scientifiques de niveau recherche, publiés ou non, émanant des établissements d'enseignement et de recherche français ou étrangers, des laboratoires publics ou privés. 


\title{
Control of aversion by glycine-gated GluN1/GluN3A NMDA
}

\section{receptors in the adult Medial Habenula}

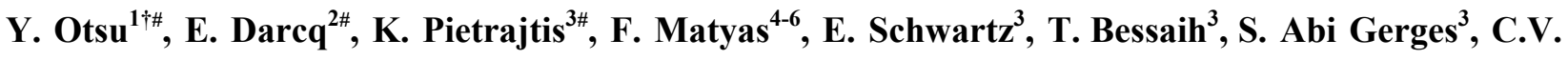 \\ Rousseau $^{1 \ddagger}$, T. Grand ${ }^{1}$, S. Dieudonné ${ }^{1}$, P. Paoletti ${ }^{1}$, L. Acsady ${ }^{4}$, C. Agulhon ${ }^{7}$, B.L. Kieffer ${ }^{2}$, M.A. \\ $\operatorname{Diana}^{3} *$
}

${ }^{1}$ Institut de Biologie de l'École Normale Supérieure (IBENS), INSERM U1024, CNRS UMR8197, École Normale Supérieure, Université PSL, Paris, France.

${ }^{2}$ Department of Psychiatry, School of Medicine, Douglas Hospital Research Center, McGill University, Montreal, QC, Canada.

${ }^{3}$ Sorbonne Université, UPMC Université Paris 06, INSERM, CNRS, Neurosciences Paris Seine-Institut de Biologie Paris Seine (NPS-IBPS), 75005 Paris, France.

${ }^{4}$ Laboratory of Thalamus Research, Institute of Experimental Medicine, Hungarian Academy of Sciences, Budapest, Hungary.

${ }^{5}$ Research Centre for Natural Sciences Institute of Cognitive Neuroscience and Psychology, Budapest, 1117 Hungary.

${ }^{6}$ Department of Anatomy and Histology, University of Veterinary Medicine, Budapest, 1078 Hungary.

${ }^{7}$ Integrative Neuroscience and Cognition Center, CNRS UMR8002, Glia-Glia and Glia-Neuron Interactions Group, Paris Descartes University, 45 rue des Saints-Pères, 75006, Paris, France.

†Present address: Pain Management Research Institute, Kolling Institute of Medical Research, Northern Clinical School, The University of Sydney and Royal North Shore Hospital, St. Leonards, NSW, Australia.

${ }^{\ddagger}$ Present address: Neural circuit dynamics and decision making, Pasteur Institute, 25 rue du Dr Roux, 75015 Paris, France. 
\# Equal contributions from these authors.

*Corresponding author. E-mail: marco.diana@upmc.fr 
The unconventional N-methyl-D-aspartate (NMDA) receptor subunits GluN3A/B can generate excitatory conductances purely activated by glycine, when associated with the other glycine-binding subunit GluN1. However, functional GluN1/GluN3 receptors have not been identified in native adult tissues. We discovered that GluN1/GluN3A receptors are operational in neurons of the mouse adult medial habenula $(\mathrm{MHb})$, an epithalamic area controlling aversive physiological states. In the absence of glycinergic neuronal specializations in the $\mathrm{MHb}$, glial cells tuned neuronal activity via GluN1/GluN3A receptors. Reducing GluN1/GluN3A receptor levels in the MHb prevented place aversion conditioning. Our study extends the physiological and behavioral implications of glycine by demonstrating its control of negatively-valued emotional associations via excitatory glycinergic NMDA receptors.

\section{ONE SENTENCE SUMMARY}

Physiology of glycine NMDA receptors 
Glycine is a major inhibitory neurotransmitter of the central nervous system, acting via anion-permeable receptors. It is also a well-characterized co-agonist of excitatory N-methyl-D-aspartate receptors (NMDARs) via GluN1 subunits (1).

In addition, glycine binds the unconventional NMDAR subunits GluN3A/B, which generate atypical glutamate-activated triheteromeric NMDARs with GluN1 and GluN2 subunits (2), and glycine-gated diheteromeric excitatory complexes with GluN1 (3). GluN3B is significantly expressed only in caudal areas (4). GluN3A expression is broader, but assumed to be limited to early development (2). Mainly examined in recombinant systems $(4,5)$, native GluN1/GluN3ARs have been identified in the juvenile hippocampus (8), but never in adult neurons.

We found strong immunohistochemical expression of GluN3A subunits in the ventral subdivision of the medial habenula $(\mathrm{MHb})$ of adult mice (Fig.1A; $(9))$, an area mediating aversive behaviors $(10-14)$.

We investigated GluN3A-immunostained sections with electron microscopy to identify its ultrastructural localization. Frequently in juxtaposition with glial structures, all the 3,3-diaminobenzidine (DAB)-labelled profiles were identified as postsynaptic dendrites and somata ( $\mathrm{n}=92$; Fig.1B). Supported by further confocal microscopy results (Fig.S1), these data demonstrated that GluN3A subunits were abundantly expressed in adult $\mathrm{MHb}$ neurons.

We examined whether GluN3A subunits formed operational GluN1/GluN2/GluN3ARs. These receptors show reduced rectification compared to GluN1/GluN2 NMDARs (1). We thus examined the currentvoltage (I-V) curves of synaptic (17), and puff-evoked NMDAR currents in MHb neurons from wild type (WT) and GluN3AKO (15) mice, in which excitatory transmission to the MHb is not modified (Fig.S2). No significant differences were found (Fig.1Ca\&Cb), suggesting absence of functional receptors.

To investigate whether glycine-activated GluN1/GluN3ARs were operational, glycine (1-10mM) was pressure-ejected while recording spontaneous firing activity (17) in the loose cell-attached configuration (LCA). In all tested WT neurons, glycine puffs $(300-500 \mathrm{~ms})$ potently increased firing in the presence of D-2-amino-5-phosphonovalerate (D-APV) and strychnine (Fig.1D). This excitatory effect was not due to conventional NMDARs, because it was present in GluN2AKO mice (Fig.1D), where GluN1/GluN2 
NMDARs are nearly undetectable (17). The effect on firing activity was absent in GluN3AKO mice (Fig.1D), supporting the presence of GluN1/GluN3ARs in the MHb.

Glycine puffs induced rapidly rising and inactivating inward currents in voltage clamp recordings of both WT and GluN2AKO ex-vivo MHb neurons performed in the presence of D-APV and strychnine. The currents could not be elicited in GluN3AKO mice (Fig.1E). Similarly to recombinant systems $(5,6)$, the glycine-evoked currents showed slight outward rectification (Fig.1G).

We investigated the pharmacology of the glycine-induced currents. In recombinant systems occupation of the higher affinity GluN3A site activates the receptor, whereas glycine binding to GluN1 entrains rapid desensitization $(5,6)$. We recently discovered that the GluN1 antagonist (1S)-1-[[(7-Bromo-1,2,3,4tetrahydro-2,3-dioxo-5-quinoxalinyl)methyl]amino]ethyl]phosphonic acid (CGP78608) enhanced

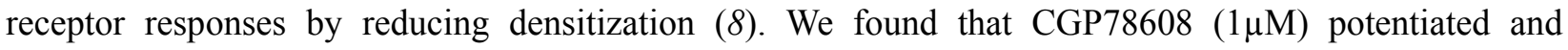
prolonged the responses in WT but not GluN3AKO mice (Fig.2A). 6-Cyano-7-nitroquinoxaline-2,3-dione (CNQX), 5,7-Dichlorokinurenic acid (5,7-DCKA) and D-serine inhibit the currents produced by GluN1/GluN3Rs $(3,5,6,8)$. These drugs potently inhibited the responses to glycine also in MHb neurons (Fig.2B). Direct applications of D-serine increased neuronal excitability (Fig.S4) and elicited currents (Fig. 2C) to smaller extents than glycine (3). With the exception of zinc, which had no effects ((7); Fig.S5), the pharmacological profile of the native currents thus mirrored that of recombinant GluN1/GluN3Rs.

We injected the MHb with a short hairpin ribonucleic acid (shRNA)-expressing adeno-associated virus targeting the GluN3A subunit (AAV5-shRNA-GluN3A; (18)). The virus efficiently reduced both the messenger RNA levels of GluN3A in the MHb (Fig.2D), and the amplitude of the glycine-induced currents compared to scrambled RNA-expressing mice (Fig.2D).

The permeability of GluN1/GluN3ARs to calcium $\left(\mathrm{Ca}^{2+}\right)$ remains uncertain $(3,19)$. We examined this question by first analyzing in human embryonic kidney (HEK) cells a GluN1/GluN3AR variant with potentiated glycine responses (GluN1-F484A/GluN3A; $(4,7)$ ). Increasing the extracellular $\mathrm{Ca}^{2+}$ concentration led to a shift of the reversal potential of the responses to glycine (Fig.2Ea), which 
demonstrated significant $\mathrm{Ca}^{2+}$ permeability, although smaller than for WT GluN1/GluN2A receptors (Fig.S6).

Using two photon microscopy in the presence of synaptic and $\mathrm{Ca}^{2+}$ channel blockers, we could detect glycine-evoked $\mathrm{Ca}^{2+}$ transients originating from GluN1/GluN3ARs in ex-vivo MHb cells (Fig.2Eb). We concluded that also native GluN1/GluN3A receptors were permeable to $\mathrm{Ca}^{2+}$.

We then searched for physiological sources of glycine. We previously found that the MHb was completely devoid of glycinergic neuronal specializations (Fig.S1; $(20)$ ). We thus tested whether glial cells could control extracellular glycine levels in mice expressing the excitatory Designer Receptor Exclusively Activated by Designer Drugs (DREADD) hM3Dq under the control of the promoter of the glial fibrillary protein (GFAP). In these mice hM3DqR activation triggers $\mathrm{Ca}^{2+}$ elevations specifically in glial cells (21). We confirmed that hM3DqR expression was exclusively glial (Fig.3A\&S7).

To determine whether GluN1/GluN3ARs mediated glia-neuron interactions in the MHb, we recorded exvivo spontaneous firing activity in GFAP-hM3Dq mice (Fig.3). Application of the hM3DqR agonist clozapine-N-oxide $(\mathrm{CNO} ; 10 \mu \mathrm{M})$, produced rapid firing rate increases.

Pre-incubation with 5,7-DCKA and CNQX strongly reduced the effect of CNO, suggesting a substantial contribution from GluN1/GluN3ARs (Fig.3). Interestingly, CGP78608 application significantly augmented basal firing rates (Fig.S3), indicating that ambient glycine may suffice to bind GluN3A. The potentiation of the firing rate triggered by $\mathrm{CNO}$ was instead reduced by CGP78608 pre-incubations.

Furthermore, the effect of CNO was significantly smaller in GFAP-hM3D mice injected with the AAV5shRNA-GluN3A-GFP than with AAV5-scrRNA-GluN3A-GFP virus (Fig.3). In contrast to GlyT2 (Fig.S1), we found expression of the membrane glycine transporter GlyT1 in MHb glia (Fig.S8), which can contribute to glial glycine accumulation (22). In the presence of the GlyT1-specific blocker N-[(3R)3-([1,1'-Biphenyl]-4-yloxy)-3-(4-fluorophenyl)propyl]-N-methylglycine (ALX5407), CNO applications increased firing rates to greater values than in control (Fig.3C\&D), likely because of greater build-up of extracellular glycine levels. Together these experiments suggested that glial cells potentiated neuronal activity via activation of GluN1/GluN3ARs. 
We finally examined whether GluN1/GluN3ARs in the adult MHb were behaviorally relevant, in mice injected with either the AAV5-shRNA-GluN3A-GFP, or the AAV5-scrRNA-GluN3A-GFP virus (Fig.S9). First, no differences were detected in locomotor and exploratory activity in an open field arena (Fig.4A). In contrast the test mice spent significantly less time in the open arms of an elevated place maze, suggesting that reduced GluN1/GluN3AR levels in the MHb were mildly anxiogenic (Fig.4A\&B).

GluN1/GluN3ARs in the MHb did not modulate learning and memory capabilities because test and control mice scored similarly in a novel object recognition test (Fig.4C).

The $\mathrm{MHb}$ can contribute to the development of negatively-valued emotional states. We thus examined the behavioral outcomes of a fear conditioning protocol (Fig.4D). We found no difference between AAV5shRNA- and AAV5-scrRNA-injected mice in the freezing time elicited either by the cued, or the contextual stimulus (Fig.4D).

Finally, we examined lithium-induced conditioned place aversion (CPA), because this paradigm relies on intact $\mathrm{MHb}$ function $(23,24)$. In contrast to AAV5-scrRNA animals, lithium-treated AAV5-shRNA mice did not develop aversion for the conditioned compartment (Fig.4E). Overall, these results indicate that impaired GluN3A signaling in the MHb can alter the capability of associating negatively-valued external conditions with internal aversive states.

In addition to its ubiquitous role as inhibitory neurotransmitter, glycine can thus exert excitatory actions via unconventional GluN1/GluN3A NMDARs. Our study unveils a functional role of this aspect of glycine physiology by demonstrating that full expression of GluN1/GluN3ARs in the MHb is mandatory for modifying the internal emotional landscape in response to specific environmental challenges. 


\section{REFERENCES and NOTES}

1. P. Paoletti, Molecular basis of NMDA receptor functional diversity. Eur J Neurosci. 33, 1351-1365 (2011).

2. I. Perez-Otano, R. S. Larsen, J. F. Wesseling, Emerging roles of GluN3-containing NMDA receptors in the CNS. Nat Rev Neurosci. 17, 623-635 (2016).

3. J. E. Chatterton et al., Excitatory glycine receptors containing the NR3 family of NMDA receptor subunits. Nature. 415, 793-798 (2002).

4. K. Matsuda, Y. Kamiya, S. Matsuda, M. Yuzaki, Cloning and characterization of a novel NMDA receptor subunit NR3B: A dominant subunit that reduces calcium permeability. Mol. Brain Res. 100, 43-52 (2002).

5. C. Madry et al., Principal role of NR3 subunits in NR1/NR3 excitatory glycine receptor function. Biochem Biophys Res Commun. 354, 102-108 (2007).

6. M. Awobuluyi et al., Subunit-specific roles of glycine-binding domains in activation of NR1/NR3 N-methylD-aspartate receptors. Mol Pharmacol. 71, 112-122 (2007).

7. C. Madry, H. Betz, J. R. Geiger, B. Laube, Supralinear potentiation of NR1/NR3A excitatory glycine receptors by Zn2+ and NR1 antagonist. Proc Natl Acad Sci U S A. 105, 12563-12568 (2008).

8. T. Grand, S. Abi Gerges, M. David, M. A. Diana, P. Paoletti, Unmasking GluN1/GluN3A excitatory glycine NMDA receptors. Nat Commun. 9, 4769 (2018).

9. R. S. Larsen et al., NR3A-containing NMDARs promote neurotransmitter release and spike timingdependent plasticity. Nat Neurosci. 14, 338-344 (2011).

10. M. Agetsuma et al., The habenula is crucial for experience-dependent modification of fear responses in zebrafish. Nat Neurosci. 13, 1354-1356 (2010).

11. C. D. Fowler, Q. Lu, P. M. Johnson, M. J. Marks, P. J. Kenny, Habenular alpha5 nicotinic receptor subunit signalling controls nicotine intake. Nature. 471, 597-601 (2011).

12. A. Gorlich et al., Reexposure to nicotine during withdrawal increases the pacemaking activity of cholinergic habenular neurons. Proc Natl Acad Sci U S A. 110, 17077-17082 (2013).

13. J. Zhang et al., Presynaptic Excitation via GABAB Receptors in Habenula Cholinergic Neurons Regulates Fear Memory Expression. Cell. 166, 716-728 (2016).

14. S. Molas, S. R. DeGroot, R. Zhao-Shea, A. R. Tapper, Anxiety and Nicotine Dependence: Emerging Role of the Habenulo-Interpeduncular Axis. Trends Pharmacol Sci. 38, 169-180 (2017). 
15. S. Das et al., Increased NMDA current and spine density in mice lacking the NMDA receptor subunit NR3A. Nature. 393, 377-381 (1998).

16. G. Tong et al., Modulation of NMDA receptor properties and synaptic transmission by the NR3A subunit in mouse hippocampal and cerebrocortical neurons. J Neurophysiol. 99, 122-132 (2008).

17. Y. Otsu et al., Functional Principles of Posterior Septal Inputs to the Medial Habenula. Cell Rep. 22, 693705 (2018).

18. T. Yuan et al., Expression of cocaine-evoked synaptic plasticity by GluN3A-containing NMDA receptors. Neuron. 80, 1025-1038 (2013).

19. J. C. Pina-Crespo et al., Excitatory glycine responses of CNS myelin mediated by NR1/NR3 "NMDA" receptor subunits. J Neurosci. 30, 11501-11505 (2010).

20. K. Giber et al., A subcortical inhibitory signal for behavioral arrest in the thalamus. Nat Neurosci. 18, 562$568(2015)$.

21. C. Agulhon et al., Modulation of the autonomic nervous system and behaviour by acute glial cell Gq proteincoupled receptor activation in vivo. J Physiol. 591, 5599-5609 (2013).

22. F. Zafra et al., Glycine transporters are differentially expressed among CNS cells. J Neurosci. 15, 3952-3969 (1995).

23. E. Darcq et al., RSK2 signaling in brain habenula contributes to place aversion learning. Learn Mem. 18, 574-578 (2011).

24. L. J. Boulos et al., Mu opioid receptors in the medial habenula contribute to naloxone aversion. Neuropsychopharmacology, 1-9 (2019).

25. Y. Zuo et al., Fluorescent proteins expressed in mouse transgenic lines mark subsets of glia, neurons, macrophages, and dendritic cells for vital examination. J Neurosci. 24, 10999-11009 (2004).

26. Y. Yang et al., Molecular comparison of GLT1+ and ALDH1L1+ astrocytes in vivo in astroglial reporter mice. Glia. 59, 200-207 (2011).

27. K. Sakimura et al., Reduced hippocampal LTP and spatial learning in mice lacking NMDA receptor epsilon 1 subunit. Nature. 373, 151-155 (1995).

28. H. U. Zeilhofer et al., Glycinergic neurons expressing enhanced green fluorescent protein in bacterial artificial chromosome transgenic mice. J Comp Neurol. 482, 123-141 (2005). 
29. Y. Otsu et al., Activity-dependent gating of calcium spikes by A-type $\mathrm{K}+$ channels controls climbing fiber signaling in Purkinje cell dendrites. Neuron. 84, 137-151 (2014).

30. M. A. Diana et al., T-type and L-type Ca2+ conductances define and encode the bimodal firing pattern of vestibulocerebellar unipolar brush cells. J Neurosci. 27, 3823-3838 (2007).

31. A. D. Randall, R. W. Tsien, Contrasting biophysical and pharmacological properties of T-type and R-type calcium channels. Neuropharmacology. 36, 879-893 (1997).

32. F. Viana et al., Mibefradil (Ro 40-5967) blocks multiple types of voltage-gated calcium channels in cultured rat spinal motoneurones. Cell Calcium. 22, 299-311 (1997).

33. S. I. McDonough, B. P. Bean, Mibefradil Inhibition of T-Type Calcium Channels in Cerebellar Purkinje Neurons. Mol. Pharmacol. 54, 1080-1087 (2018).

34. J. Schindelin et al., Fiji: an open-source platform for biological-image analysis. Nat. Methods. 9, 676-82 (2012).

35. E. Darcq et al., RSK2 signaling in medial habenula contributes to acute morphine analgesia. Neuropsychopharmacology. 37, 1288-1296 (2012).

36. C. V. Rousseau et al., Mixed Inhibitory Synaptic Balance Correlates with Glutamatergic Synaptic Phenotype in Cerebellar Unipolar Brush Cells. J. Neurosci. 32, 4632-4644 (2012).

37. P. Chu Sin Chung et al., A novel anxiogenic role for the delta opioid receptor expressed in GABAergic forebrain neurons. Biol Psychiatry. 77, 404-415 (2015).

38. M. L. Mayer, G. L. Westbrook, Permeation and block of N-methyl-D-aspartic acid receptor channels by divalent cations in mouse cultured central neurones. J Physiol. 394, 501-527 (1987).

39. A. C. Meirsman, A. Robe, A. de Kerchove d'Exaerde, B. L. Kieffer, GPR88 in A2AR Neurons Enhances Anxiety-Like Behaviors. eNeuro. 3 (2016), doi:10.1523/ENEURO.0202-16.2016.

40. O. Mohamad, M. Song, L. Wei, S. P. Yu, Regulatory roles of the NMDA receptor GluN3A subunit in locomotion, pain perception and cognitive functions in adult mice. $J$ Physiol. 591, 149-168 (2013). 


\section{ACKNOWLEDGMENTS}

We thank M.Galante, R.Lambert and N.Leresche for critically reading the manuscript, M.McNicholas and S.Kirchherr for assistance during behavioral experiments, and B.Mathieu at the IBENS Imaging Facility. N. Nakanishi and S.Lipton (Scintillon Institute) provided the GluN3AKO mice, M.Mishina (Tokyo University) the GluN2AKO line. The anti-GluN3A antibody was a gift from M.Watanabe (Hokkaido University). We thank C.Bellone (Geneva University) for the scr/shRNA-expressing viruses.

\section{DATA AND MATERIALS AVAILABILITY}

Data values and statistics are included as supplementary material.

\section{FUNDING}

This study was supported by fellowships (NKTH-)ANR-09-BLAN-0401 to S.D. M.A.D. and L.A., by ANR-17-CE16-0014 to P.P., S.D., B.L.K. and M.A.D., by Emergence Sorbonne (No.S17JRSU003) and CNRS (PICS No.7415) to M.A.D., by the European Research Council (ERC No.693021) to P.P., by ERCFRONTHAL (No.742595) to L.A., by grants No.FK124434 and No.2017-1.2.1-NKP-2017-00002 to F.M., by the National Institute of Drug Abuse (No.05010) and National Institute on Alcohol Abuse and Alcoholism (No.16658) to B.L.K. C.A. was supported by a Paris School of Neuroscience "Chair of Excellence" and by a NARSAD Y.I. Award.

\section{AUTHOR CONTRIBUTIONS}

M.A.D. designed and developed the project. Y.O. and M.A.D. performed the electrophysiology with K.P., S.A.G., T.B. and E.S. K.P., C.V.R. and C.A. performed confocal immunohistochemistry, F.M. the EM under supervision of L.A. E.D. performed the behavioral tests under the supervision of B.L.K., with M.A.D. and K.P. T.G. performed the HEK experiments under supervision of P.P. S.D. contributed equipment. C.A. provided transgenic mice. M.A.D. wrote the manuscript, edited by all authors. 


\section{COMPETING INTERESTS}

Authors declare no competing interests.

\section{SUPPLEMENTARY MATERIALS}

Materials and Methods

Table S1

Figure S1 - S9

References (25 - 40) 


\section{Figures}

A

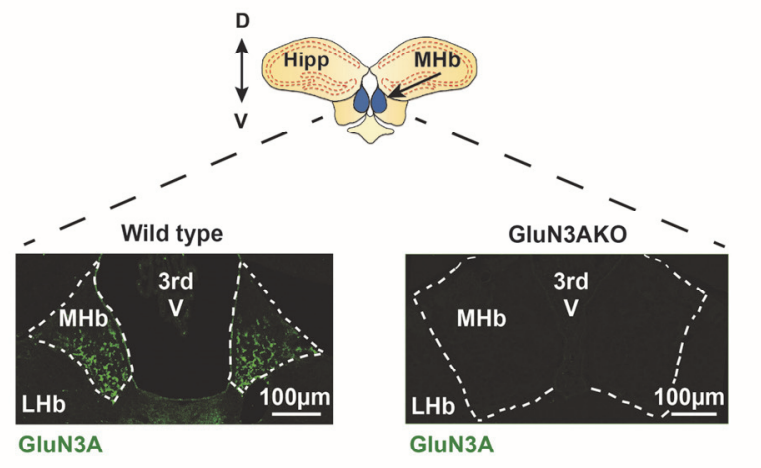

B

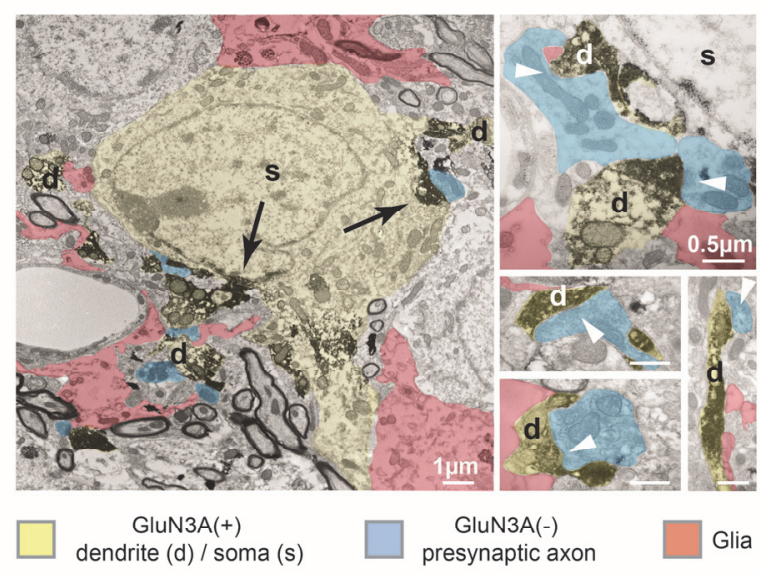

C
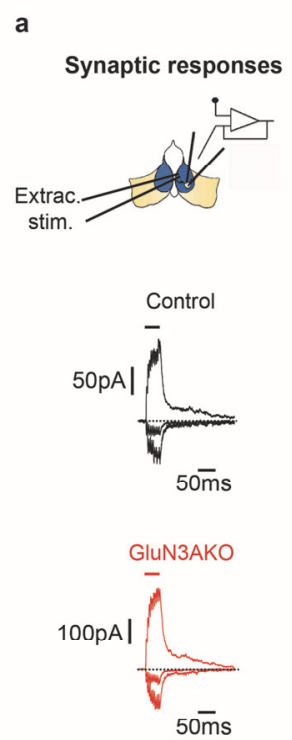

b

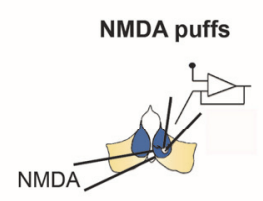

Control
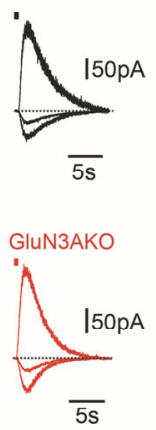

$5 s$

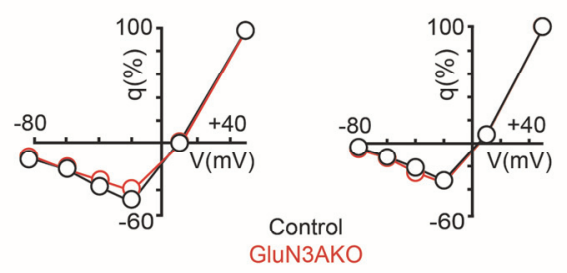

D

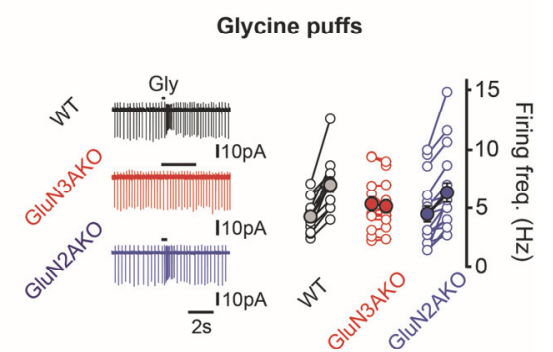

E

Glycine puffs

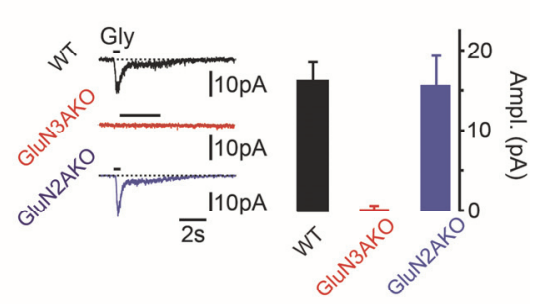

F

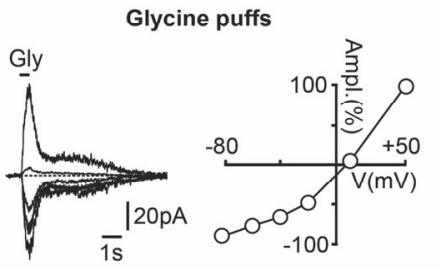

Fig.1.Functional GluN1/GluN3ARs in the adult MHb. Both confocal (A) and EM (B) demonstrated that GluN3A subunits are expressed in the ventral MHb. DAB EM staining (B, black deposits) was detected in dendrites (yellow compartments, d), close to glial extensions (red), rarely in somas (black arrows, s), but never in axons (blue, arrowheads highlighting presynaptic specializations). (C)GluN1/GluN2/GluN3ARs are not functional in the MHb. No difference was found in the rectification of NMDAR currents in WT (black) and GluN3AKO (red) mice, elicited by extracellular stimulation (a) or pressure-ejected NMDA (b). (D)Glycine puffs increased firing rates in MHb cells from control and GluN2AKO mice, but not GluN3AKO animals. (E, F)Similarly to heterologous GluN1/GluN3R currents, glycine induced outwardly rectifying, rapidly rising and inactivating currents in control and GluN2AKO, but not GluN3AKO neurons. Data are illustrated as averages \pm s.e.m. 
A

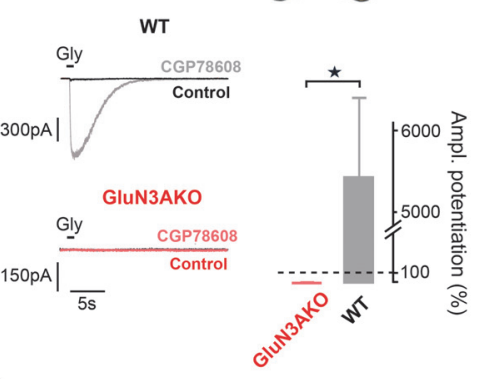

B

Glycine puffs
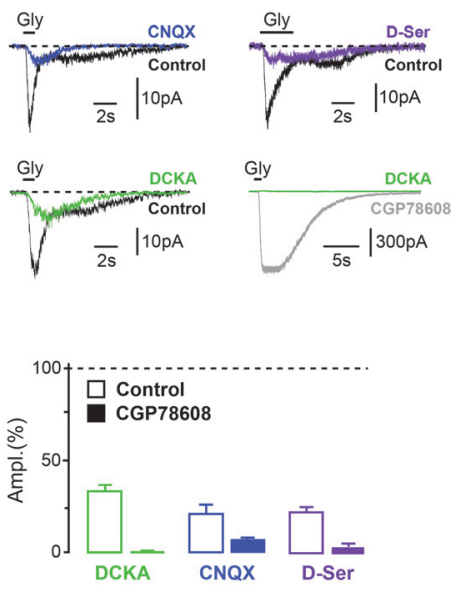

C

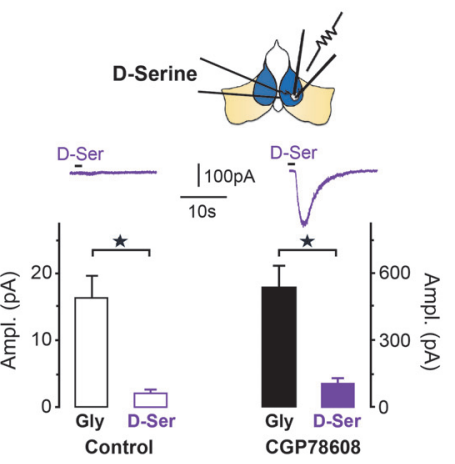

D
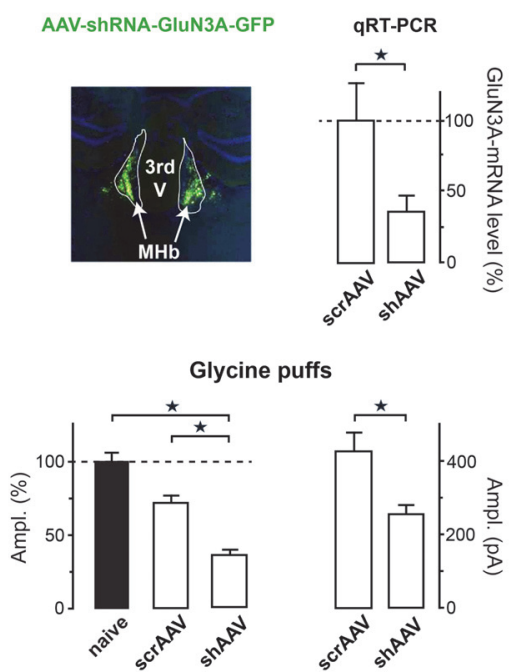

E

a

HEK cells

Glycine puffs

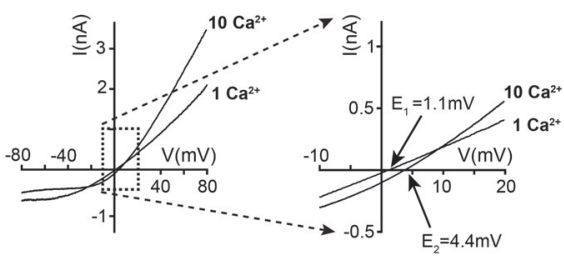

b

Glycine puffs
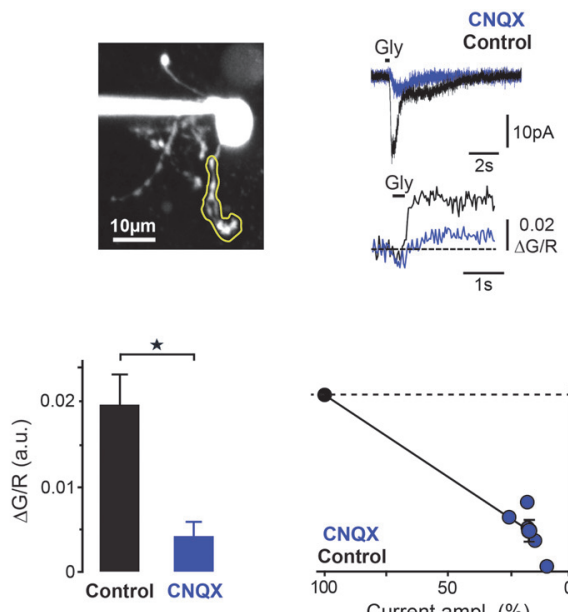

Fig.2.Properties of GluN1/GluN3Rs in the MHb. (A)GluN1 subunit block with CGP78608 potentiated glycine-elicited currents. (B)Bath applications of CNQX (blue), 5,7-DCKA (green) and D-serine (purple) antagonized control and potentiated GluN1/GluN3AR currents. (C) Pressure-ejected D-serine had only partial agonist effects on GluN1/GluN3ARs. (D)Viral expression in the MHb of a GluN3A-targeting shRNA led to reduction of GluN3A mRNA levels, and of glycine-induced currents with respect to scrambled RNA-expressing mice. Percentage values and absolute amplitudes are illustrated in the lower graphs. (E)GluN1/GluN3ARs are $\mathrm{Ca}^{2+}$ permeable. Changing extracellular $\mathrm{Ca}^{2+}$ concentrations led to a significant reversal potential shift (a, highlighted on the right) in heterologous systems expressing GluN3A and point-mutated, glycine-insensitive GluN1 subunits. In the presence of synaptic receptor antagonists and $\mathrm{Ca}^{2+}$ channel blockers, two-photon imaging revealed glycine-elicited $\mathrm{Ca}^{2+}$ transients in $e x$ vivo $\mathrm{MHb}$ neurons (b). Data are illustrated as averages \pm s.e.m. 
A

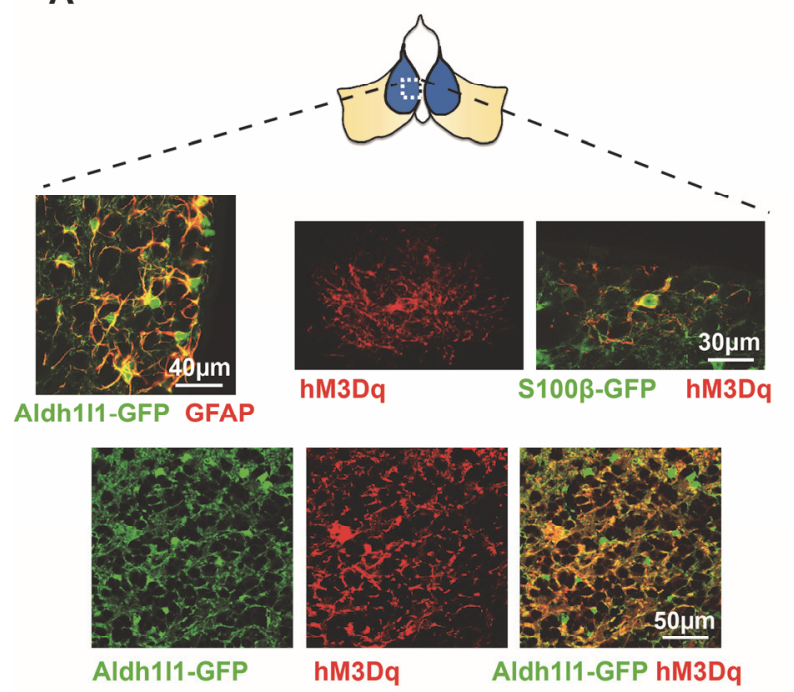

C

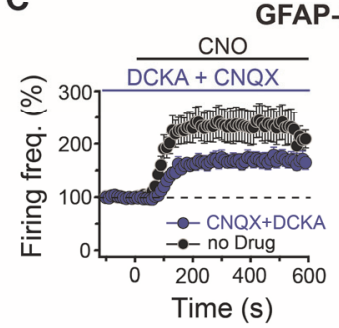

GFAP-hM3Dq mice
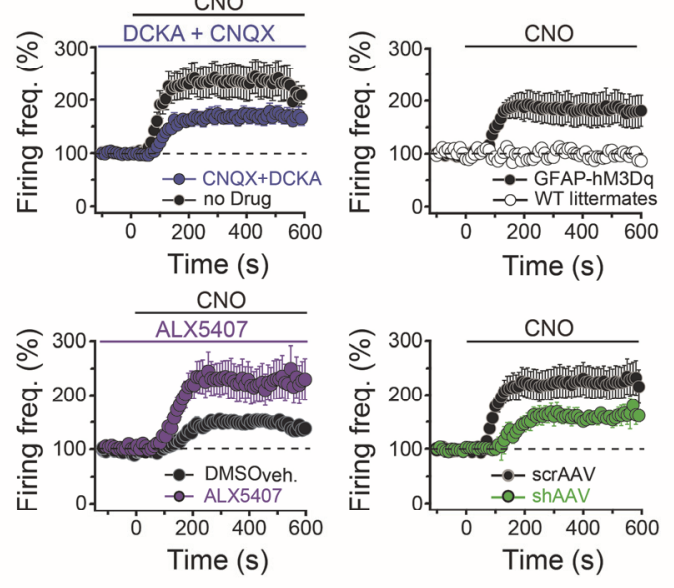

B
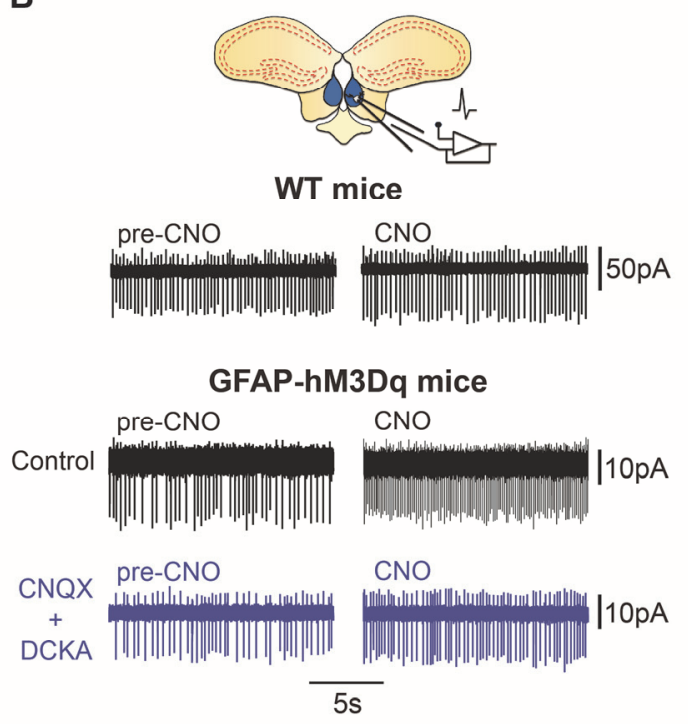

D

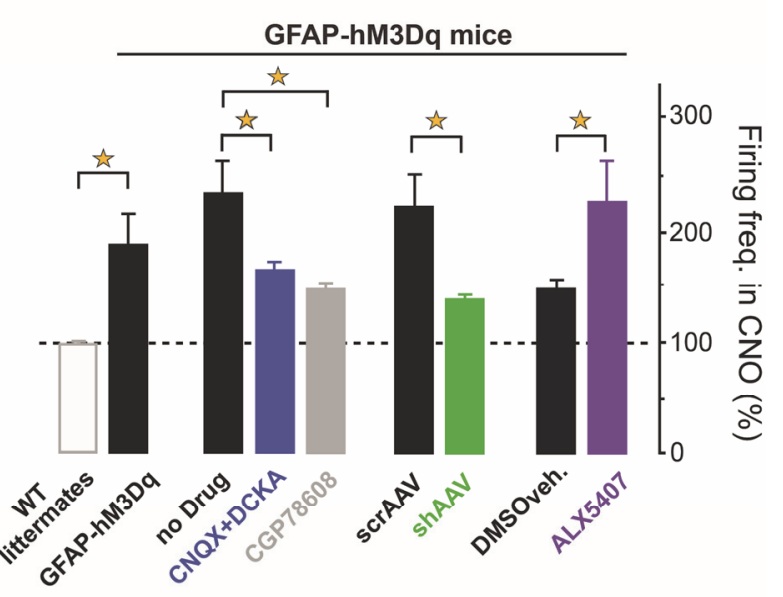

Fig.3.Glial activation in GFAP-hM3Dq mice increases neuronal excitability via GluN1/GluN3ARs.

(A)The specific expression of $\mathrm{hM} 3 \mathrm{Dq}$ receptors in $\mathrm{MHb}$ glia was demonstrated by the colocalization of GFAP and GFP in aldehyde dehydrogenase-1 family member L1-green fluorescent protein (Aldh111-GFP) mice, and of hM3DqRs and GFP in GFAP-hM3Dq::Aldh111-GFP and GFAP-hM3Dq::S100ß-GFP mice. (B)CNO applications increased spontaneous firing rates of MHb neurons. Representative traces preceding and following $\mathrm{CNO}$ are shown for specified experiments. The average time courses (C) and quantifications (D) of the CNO effects are depicted for all the experiments. The smaller increase of the 
firing rate in CGP78608 than in control likely derives from reduced affinity for glycine in the drug presence $((8))$. Data are illustrated as averages \pm s.e.m. 
A

Open Field Exploration
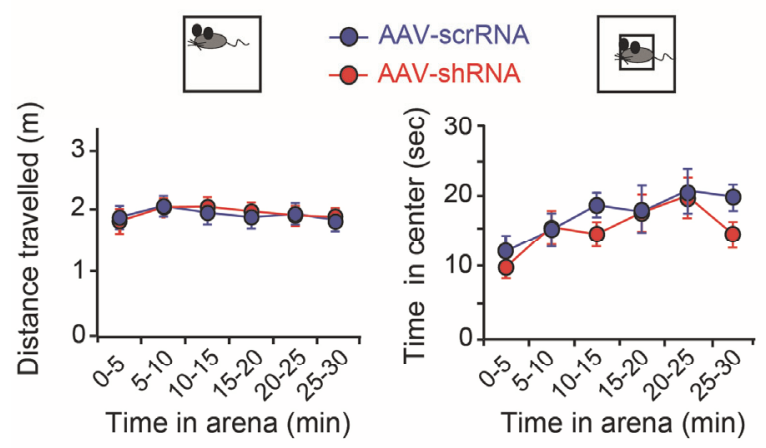

D

Fear Conditioning

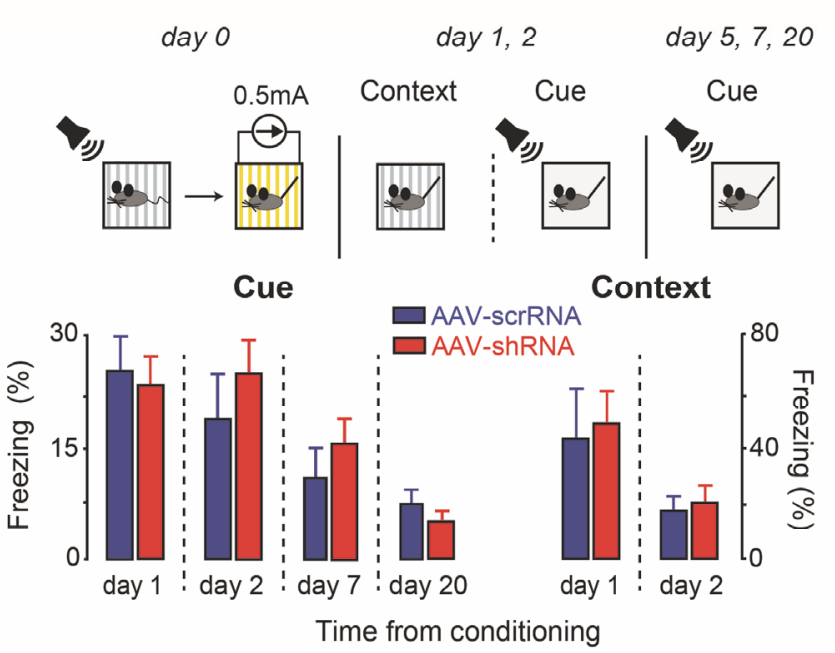

B

Elevated Plus Maze

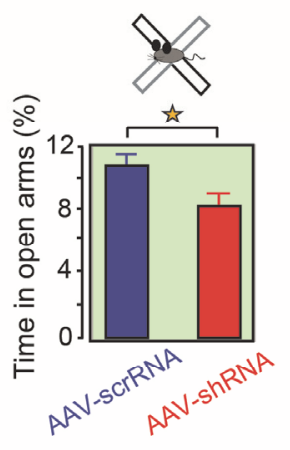

E
C

Novel Object Recognition

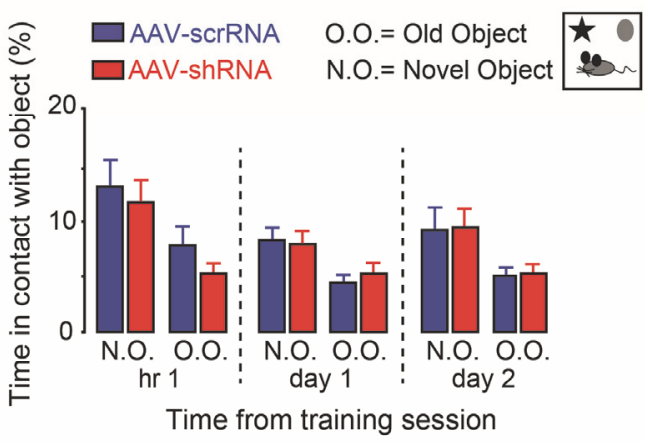

Conditioned Place Aversion
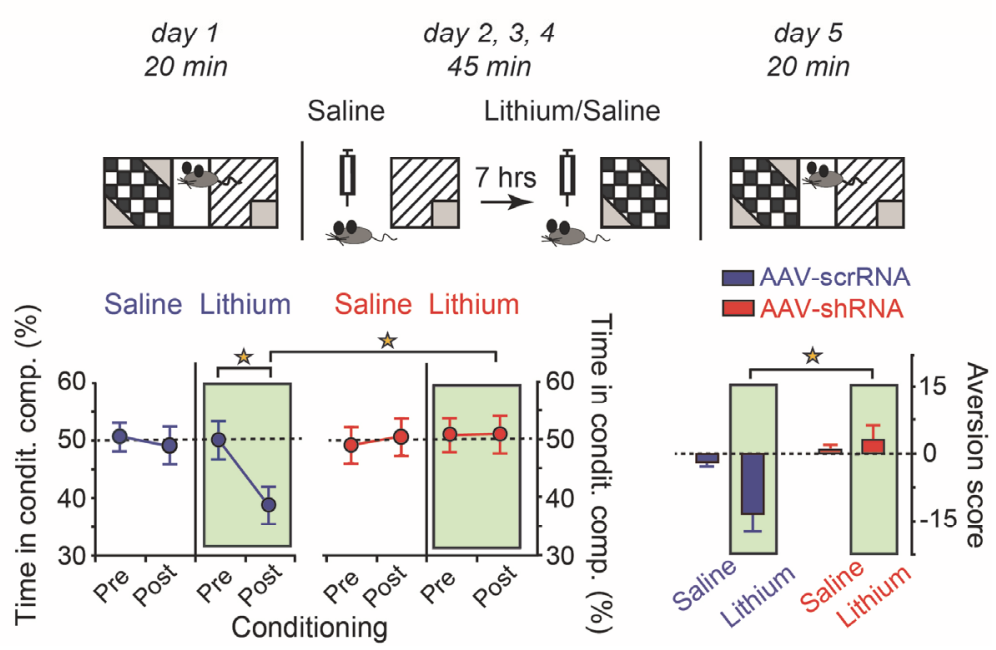

Fig.4.MHb GluN1/GluN3ARs control place aversion conditioning. (A)No difference was detected between AAV-shRNA-GluN3A- and AAV-scrRNA-GluN3A-injected mice in the distance traveled in an open field and in the time spent in its center. (B)Knocking-down MHb GluN3A expression was mildly anxiogenic as indicated by the shorter time spent by GluN3A-deficient mice in the open arms of an elevated plus maze. Object exploration times and cue- and context-induced freezing were similar in novel object recognition $(\mathbf{C})$ and fear conditioning tests (D), respectively. Following lithium conditioning, AAVshRNA-GluN3A-injected mice developed no aversion for the malaise-associated compartment in contrast to scrRNA-expressing animals (E). Data are illustrated as averages \pm s.e.m. 